\title{
BIOREEFTEK UNTUK KONSERVASI TERUMBU KARANG DI KECAMATAN SUNGAI RAYA KEPULAUAN KABUPATEN BENGKAYANG
}

\author{
Frangky Fransiskus Tumion ${ }^{1)}$, Sadri ${ }^{1)}$, Lukas Wikbowo Sasongko ${ }^{3)}$ \\ ${ }^{1}$ Jurusan Ilmu Kelautan dan Perikanan, Politeknik Negeri Pontianak \\ ${ }^{2}$ Jurusan Ilmu Kelautan dan Perikanan, Politeknik Negeri Pontianak \\ ${ }^{3}$ Jurusan Ilmu Kelautan dan Perikanan, Politeknik Negeri Pontianak \\ Email: frangky.tumion@yahoo.com; cadrie_kobar@yahoo.com
}

\begin{abstract}
ABSTRAK
Tujuan dari program ini adalah untuk memberikan pengetahuan dan wawasan kepada masyarakat Kecamatan Sungai Raya Kepulauan khususnya Desa Pulau Lemukutan. Kecamatan Sungai Raya Kepulauan memiliki 12 pulau-pulau kecil dimana 7 pulau memiliki ekosistem terumbu karang antara lain Pulau Lemukutan, Pulau Kabung, Pulau Penata Besar, Pulau Penata Kecil, Pulau Baru, Pulau Seluas dan Pulau Randayan. Berdasarkan hasil survey pada tahun 2014 sebagian besar kondisi ekosistem terumbu karang berada pada kondisi 'sedang' dan 'rusak' kecuali di Pulau Lemukutan dan Pulau Penata Besar. Kerusakan ini terjadi karena ulah manusia dan peningkatan suhu global bumi. Tindakan rehabilitasi perlu dilakukan agar ekosistem ini dapat diperbaharui sehingga ekosistem ini dapat berkelanjutan. Rehabilitasi yang dilakukan adalah dengan penerapan teknologi bioreeftek. Bioreeftek adalah teknologi hijau yang memanfaatkan bahan alami (tempurung kelapa) sebagai media untuk penempelan larva planula karang sampai menjadi koloni individu baru (terumbu). Teknologi ini dipilih karena dianggap murah dan efektif. Konsep dari konservasi dengan bioreeftek ini adalah menanam bioreeftek di lokasi yang kondisi terumbu karangnya baik kemudian merelokasi bioreeftek ke lokasi yang memiliki terumbu karang kurang baik/rusak. Dari masa penanaman 3 bulan, pertumbuhan larva planula yang menempel pada tempurung kelapa sudah dapat dilihat baik yang terumbu karang lunak maupun keras walaupun masih sangat dini untuk dideteksi.
\end{abstract}

Kata Kunci: bioreeftek, konservasi, terumbu karang.

\section{ABSTRACT}

The aim of this program is to provide knowledge and insight to the community of Sungai Raya Kepulauan District, especially Lemukutan Island Village. Sungai Raya Kepulauan District has 12 small islands where 7 islands have coral reef ecosystems including Lemukutan Island, Kabung Island, Big Stylist Island, Small Stylist Island, Baru Island, Seluas Island and Randayan Island. Based on the survey results in 2014 most of the conditions of the coral reef ecosystem were in 'moderate' and 'damaged' conditions except on Lemukutan Island and the Big Penata Island. This damage is caused by human activity and an increase in the global temperature of the earth. Rehabilitation measures need to be taken so that this ecosystem can be renewed so that this ecosystem can be sustainable. Rehabilitation is carried out by applying bioreeftek technology. Bioreeftek is a green technology that utilizes natural material (coconut shell) as a medium for attaching coral planula larvae to become colonies of new individuals 
(reefs). This technology was chosen because it was considered cheap and effective. The concept of conservation with bioreeftek is to plant bioreeftek in locations with good coral reef conditions and then relocate bioreeftek to locations that have poor / damaged coral reefs. From the planting period of 3 months, the growth of planula larvae attached to the coconut shell can already be seen both soft and hard coral reefs although it is still very early to be detected.

Keywords: bioreeftek, conservation, coral reefs.

\section{PENDAHULUAN}

Kecamatan Sungai Raya Kepulauan merupakan salah satu kecamatan pesisir yang ada di Kabupaten Bengkayang. Kecamatan Sungai Raya Kepulauan memiliki 12 pulau-pulau kecil antara lain: Pulau Penata Besar; Pulau Penata Kecil; Pulau Seluas; Pulau Semesak; Pulau Kera; Pulau Baru; Pulau Batu Rakit; Pulau Tempurung; Pulau Kabung; Pulau Batu Payung; Pulau Lemukutan; dan Pulau Randayan. Dari sejumlah pulau tersebut, ada sebanyak 6 pulau masih belum berpenghuni dan 6 pulau sudah berpenghuni.

Ekosistem terumbu karang di Kecamatan Sungai Raya Kepulauan tersebar di perairan sekitar beberapa pulau kecil. Sudiono (2008) telah melakukan pemantauan dan pengukuran kondisi terumbu karang di Pulau Lemukutan, Pulau Kabung, Pulau Randayan, Penata Besar, Penata Kecil dan Seluas. Dari hasil pemantauan tersebut dilaporkan kondisi terumbu karang untuk untuk Pulau Kabung berada pada kondis 'baik' dan 'sedang'. Terumbu karang di Pulau
Lemukutan berada pada kondisi 'baik sekali' dan 'jelek'. Terumbu karang di Pulau Randayan berada pada kondisi 'sedang' dan 'jelek'. Terumbu karang di Penata Besar berada pada kondisi 'baik'. Terumbu karang di Pulau Penata Kecil berada kondisi 'sangat baik', dan terumbu karang di Pulau Seluas berada pada kondisi 'baik'.

Dari hasil pemantauan dan pengukuran yang dilakukan pada bulan Juni 2014 dalam rangka mendampingi Rencana Zonasi Pesisir dan Pulau-Pulau Kecil (RZWP-3-K) Kabupaten Bengkayang dilaporkan bahwa sebagian besar kondisi terumbu karang di perairan pulau-pulau kecil tersebut adalah sedang dan rusak walaupun terdapat kondisi baik sekali di beberapa titik

Tujuan dari program ini adalah untuk memberikan pengetahuan dan wawasan kepada masyarakat Kecamatan Sungai Raya Kepulauan khususnya Desa Pulau Lemukutan. Teknologi dengan bioreeftek merupakan salah satu teknik transplantasi terumbu karang yang dikembangkan sejak 2008 hingga 
sekarang. Bioreeftek merupakan teknologi yang memanfaatkan bahan alami (tempurung kelapa) sebagai media untuk penempelan larva planula karang sampai menjadi individu baru (terumbu).

Berbagai macam teknik transplantasi karang diantaranya dengan menggunakan teknik patok, penggunaan jaring, substrat, rangka serta kombinasi jaring dan substrat atau rangka. Kesulitan dalam mengaplikasikan teknik-teknik ini menjadi kendala sehingga jarang dilakukan oleh masyrakat. Bioreeftek merupakan alternatif teknologi konservasi dan rehabilitasi terumbu karang yang terbuat dari bahan alami, mudah dan efisien. Keunggulan dari bioreeftek ini adalah tidak destruktif, terbuat dari bahan alami dan mudah diperoleh, mudah diaplikasikan, biaya pembuatan murah (efisien) dan dampak negatif sangat minim.

Hingga tahun 2014, bioreeftek telah di uji coba di beberapa tempat antara lain: Taman Nasional Bunaken; Pulau Mandangin, Madura; Perairan Pemuteran; Perairan Gili Lawang; Perairan Nusa Penida, Bali; Pulau Medang, Sumbawa; Perairan Tablolong, NTT; dan Perairan Londa Lima, Sumbawa Timur.

\section{BAHAN DAN METODE}

\section{Bahan}

Bahan yang diperlukan untuk membuat bioreeftek antara lain, tempurung kelapa, pipa alumunium, rangka besi, kawat, kayu, tripleks, pasirbatu, cable ties, dan semen. Alat yang diperlukan antara lain, gurinda, sendok semen, serta tempat untuk membuat campuran semen dan pasir.

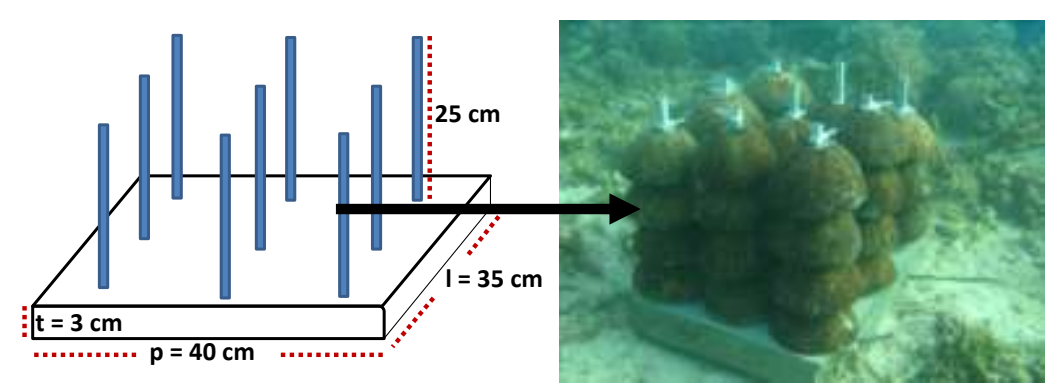

Gambar 1. Bioreeftek

\section{Metode Pelaksanaan Kegiatan}

Konsep dari konservasi dan
- Menanam bioreeftek di lokasi dengan kondisi terumbu karang baik;

rehabilitasi bioreeftek adalah: 
- Merelokasi bioreeftek yang sudah ditumbuhi karang (lebih dari 70\%) ke lokasi dengan kondisi terumbu karang kurang baik; dan

- Meletakan secara utuh bioreeftek atau masing-masing substrat (tempurung kelapa).

Tahapan pelaksanaan kegiatan pengabdian pada masyarakat yang dilakukan antara lain:

a) Memberikan peningkatan wawasan dan pengetahuan mereka tentang bioreeftek melalui pelatihan dan penyuluhan

b) Memberikan bantuan dalam bentuk bioreeftek yang telah jadi.

Mitra diberi bantuan bioreeftek yang telah jadi untuk sama-sama dilakukan pemasangan pada tempat-tempat yang memiliki kondisi terumbu karang yang baik, untuk selanjutnya nanti akan dipindahkan ke tempat yang kondisi terumbu karangnya tergolong rusak.

c) Memberikan pendampingan tentang pemantauan dan relokasi bioreeftek.
Penanaman dilakukan pada tempattempat/titik-titik yang kondisi terumbu karangnya baik sekali atau baik. Penentuan titik-titik koordinat penanaman dan relokasi dilakukan berdasarkan data hasil pemantauan pada tahun 2014 saat survey pendampingan RZW-3-K Kabupaten Bengkayang dan informasi dari masyarakat.

Pemantauan dilakukan sebanyak 2 kali setiap 4 bulan. Pemantauan setiap 4 bulan ini merujuk pada hasil penelitian yang dilakukan Balai Penelitian dan Observasi Laut (BPOL) yang menyatakan bahwa indikasi larva planula yang menempel pada substrat tempurung kelapa sudah dapat dilihat setelah 4 bulan penanaman. Pemantauan dilakukan secara visual dan menggunakan kamera bawah air untuk memfoto dan membuat rekaman.Setelah 8 bulan masa penanaman, bioreeftek dipindahkan ke lokasi yang kondisi terumbu karangnya kategori rusak.

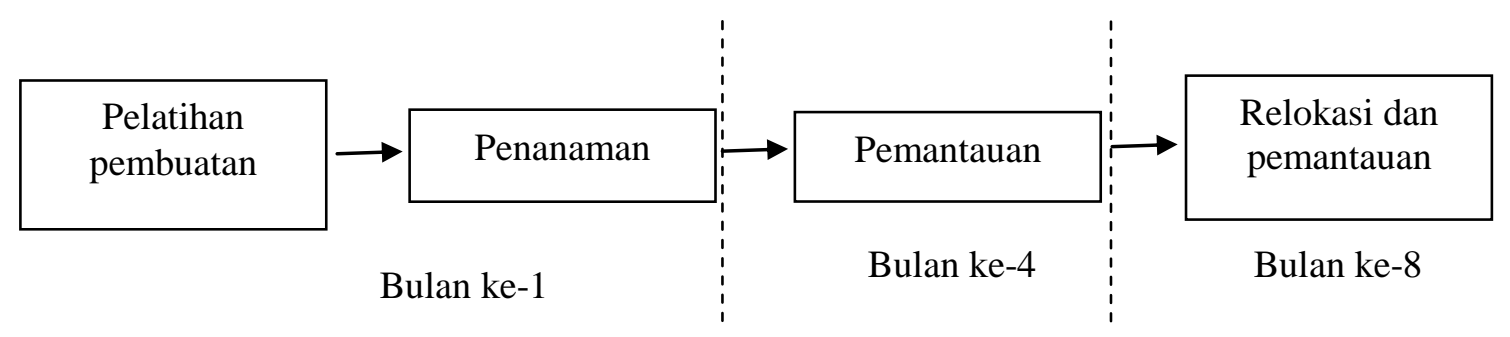

Gambar 2. Alur Proses Program Bioreeftek 
HASIL DAN PEMBAHASAN

Hasil

Pembuatan Bioreeftek Sebanyak 12 Buah

Pembuatan bioreeftek ini dilakukan di workshop Prodi Teknologi Penangkapan Ikan Politeknik Negeri Pontianak. Bioreeftek yang dibuat sebanyak 12 buah. Bioreeftek ini akan diserahkan ke Desa Pulau Lemukutan untuk kemudian dilakukan penanaman di lokasi yang telah ditentukan.

Melakukan Sosialisasi dan Pelatihan Teknologi Bioreeftek

Kegiatan sosialisasi dilaksanakan pada tanggal 1 Juni 2016 di Balai Desa Pulau Lemukutan. Sosialisasi ini berisi tentang pentingnya menjaga kelestarian terumbu karang, pengenalan teknologi bioreeftek dan praktek membuat bioreeftek. Peserta yang hadir dari Desa Pulau Lemukutan berjumlah 42 orang.

Antusias dan respek yang tinggi masyarakat Desa Pulau Lemukutan menunjukkan bahwa masyarakat desa memiliki kesadaran untuk menjaga kelestarian terumbu karang. Mereka menyadari bahwa imbas akhir dari kelestarian terumbu karang ini adalah berdampak pada kesejahteraan mereka. Jika ipteks bioreeftek ini berhasil pada ujicoba yang dilakukan di Pulau Lemukutan, maka secara sadar mereka akan menerapkan teknologi ini untuk kelestarian terumbu karang. Teknologi ini murah dan mudah untuk dibuat dan diterapkan.

\section{Penanaman Bioreeftek}

Penanaman bioreeftek dilakukan di Perairan Pulau Lemukutan tepatnya di Teluk Cina dan Bunguran. Penentuan lokasi ini berdasarkan hasil ground check kondisi ekosistem terumbu karang di Perairan Pulau Lemukutan saat Penyusunan RZWP-3-K Kabupaten Bengkayang dan hasil wawancara dengan masyarakat Desa Pulau Lemukutan. Selanjutnya relokasi bioreeftek dilakukan di Teluk Melanau yang kepadatan terumbu karangnya rendah.Bioreeftek yang ditanam sebanyak 12 buah yang dibagi menjadi 6 buah di lokasi Teluk Cina dan 6 buah di lokasi Bunguran. 


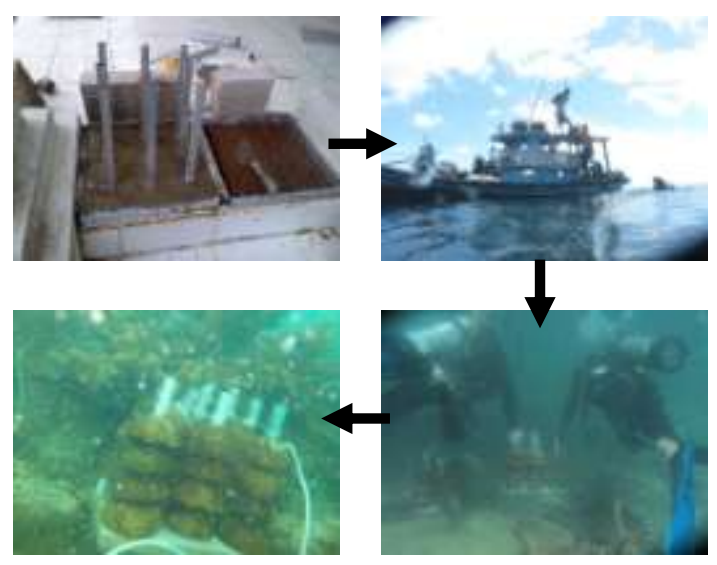

Gambar 3. Proses Pembuatan Bioreeftek dan Peletakannya

Pemantauan dan Relokasi Bioreeftek yang dihadapi saat pencarian adalah

Kegiatan pemantauan dan relokasi karena kondisi air laut pada saat itu agak ini dilakukan pada tanggal 4-5 September keruh. Setelah didapatkan bioreeftek yang 2016. Pada hari ke-1 (4 September 2016) ditanam kemudian ditandai untuk dilakukan pemcarian dan pemantauan dilakukan relokasi besok harinya. bioreeftek yang telah ditanam. Kendala

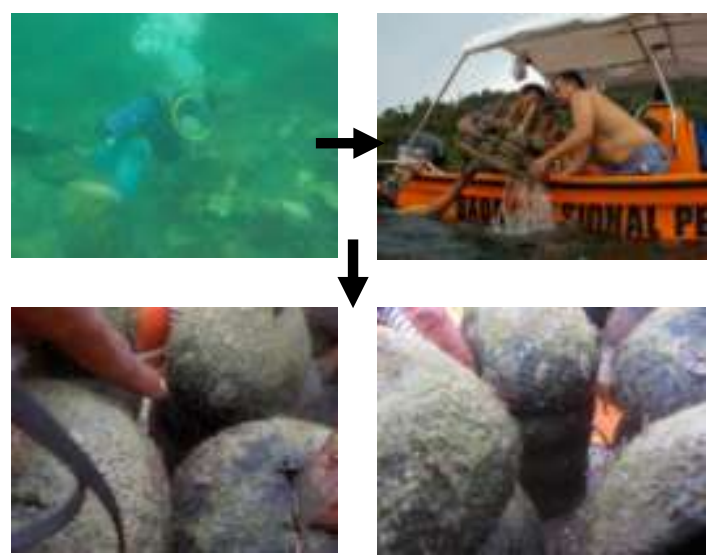

Gambar 4. Pemantauan dan Relokasi Bioreeftek

\section{Pembahasan}

Pemantauan seyogyanya dilakukan setiap 4 bulan dan relokasi dilakukan setelah 8 bulan masa penanaman (BPOL, 2014). Dari hasil penelitian yang telah dilakukan oleh BPOL bahwa larva planula yang menempel dan mulai akan jelas pertumbuhan terumbu karangnya setelah masa 8 bulan penanaman dan layak untuk direlokasi. Pertumbuhan terumbu karang ini tentunya tergantung dari faktor-faktor lingkungan seperti up welling, cahaya 
matahari, kejernihan, kedalaman, suhu perairan, salinitas, pengendapan, arus dan substrat (Santoso dan Kardono, 2008).

Selama periode 3 (tiga) bulan (2 Juni sampai dengan 5 September 2016) penanaman/peletakan bioreeftek di perairan Desa Pulau Lemukutan, pertumbuhan larva planula yang menempel pada tempurung kelapa sudah dapat dilihat baik yang terumbu karang lunak maupun keras walaupun masih sangat dini untuk dideteksi.

\section{KESIMPULAN}

Dari kegiatan Pengabdian Kepada Masyarakat (PKM) Ipteks bagi Masyarakat (IbM) Teknologi Bioreeftek untuk Konservasi Terumbu Karang di Kecamatan Sungai Raya Kepulauan Kabupaten Bengkayang, dapat disimpulkan bahwa :

a) Selama 3 bulan masa penanaman bioreeftek, cikal bakal terumbu karang sudah mulai tumbuh walaupun belum menjadi terumbu karang seutuhnya karena masa penanaman dan relokasi idealnya 8 bulan. b) Antusias yang tinggi dan respek positif masyarakat Desa Pulau Lemukutan menunjukkan tingkat kesadaran yang tinggi masyarakat Desa Pulau Lemukutan terhadap pelestarian terumbu karang

\section{REFERENSI}

Balai Penelitian dan Observasi Laut (BPOL). (2014). Presentasi Bioreeftek. Disampaikan pada Sosialisasi Hasil Penelitian di Pelabuhan Perikanan Nusantara (PPN) Pemangkat, Oktober 2014.

Balai Pengelolaan Sumberdaya Pesisir dan Laut (2014). Dokumen RZWP-3-K Kabupaten Bengkayang Tahun 2014., Kementerian Kelautan dan Perikanan RI.

Santoso, A.D. dan Kardono. (2008). Teknologi Konservasi dan Rehabilitasi Terumbu Karang. Jurnal Tek Lingkungan Vol. 9 (3) Hal. 121-226. September 2008. ISSN 1441-318X. Jakarta.

Sudiono, Gatot. (2008). Analisis Pengelolaan Terumbu Karang pada Kawasan Konservasi Laut Daerah (KKLD) Pulau Randayan dan Sekitarnya Kabupaten Bengkayang Kalimantan Barat. Thesis. Universitas Diponegoro. Semarang. 